\title{
Prediction of Polycyclic Aromatic Hydrocarbons Toxicity Using Equilibrium Partitioning Approach and Narcosis Model
}

\author{
I. A. Ololade
}

Received: 12 March 2010/ Accepted: 21 July 2010/Published online: 31 July 2010

(C) Springer Science+Business Media, LLC 2010

\begin{abstract}
The study underscores the use of equilibrium partitioning $(\mathrm{EqP})$ to determine bioavailability and the narcosis theory to estimate toxicity of PAHs to benthic invertebrates. Eight PAHs (anthracene, azuleno(2,1-b)thiophene, benz(a)anthracene, carbazole, dibenzothiophene, benz(a)azulene, dibenzo(a,h)anthracene and phenanthrene) were identified with phenanthrene and carbazole recording the highest $(6.29 \mu \mathrm{g} / \mathrm{g})$ and least $(0.06 \mu \mathrm{g} / \mathrm{g})$ concentrations at both seasons. Based on EqP and Narcosis model, the sum of PAHs toxic unit ( $\sum$ TU), at both sites is $\ll 1$, suggesting no likelihood of PAHs toxicity to benthic invertebrates. The study suggests continuous PAH monitoring especially with aquatic species due to their transfer to human via food chain.
\end{abstract}

Keywords Sediments · Polycyclic aromatic hydrocarbons · Equilibrium partitioning · Toxicity units

PAHs are among the most widely distributed organic pollutants known to be thermodynamically stable (Chen et al. 2007). Because of their low aqueous solubilities (0.003-0.34 mg/L) and high octanol-water partition coefficient $(\log$ Kow $=3.4-7.6)$, PAH compounds in aquatic

\footnotetext{
I. A. Ololade $(\bowtie)$

Department of Chemistry and Industrial Chemistry, Adekunle Ajasin University, P. M. B. 001, Akungba-Akoko, Ondo-State, Nigeria

e-mail: olisa200@yahoo.com

Present Address:

I. A. Ololade

State Key Lab Environmental Aquatic Chemistry, Research Center for Eco-environmental Sciences, Chinese Academy of Sciences, 18 Shuangqing Road, Beijing 100085, China
}

system tend to be associated with sediment and biota with reported cases of toxicity, carcinogenicity and mutagenicity (Koh et al. 2004; Kannan et al. 2005). Very few benchmarks have employed the use of equilibrium partitioning $(\mathrm{EqP})$ theory to predict the biological effects of selected organic chemicals on aquatic organisms (Di Toro et al. 1991). In all these studies, the approach has been created for the protection of both freshwater and marine organisms and is applicable to benthic and water column organisms. It is based on the premise that contaminant distributions are predictable among the different compartments of the sediment matrix based on the physical and chemical properties of the sediment components. This method assumes that there is equilibrium between sediment and interstitial water and that chemicals are partitioned between interstitial water and sediment particles. The partitioning is determined primarily by the organic carbon content of the sediment (for nonionic organics), and the partitioning behavior of each particular chemical.

In a sediment system (Fig. 1), the predominant phases involved in EqP include the sediment organic carbon and dissolved phase (i.e., interstitial water). Based on EqP, if the sediment concentration of $\mathrm{PAH}$ and concentration of sediment organic carbon $\left(f_{\mathrm{OC}}\right)$ are known, the interstitial water concentration of PAH can be predicted. PAH belongs to a class of narcotic toxicants which frequently demonstrates additive toxicity. Generally, the predicted bioavailable $\mathrm{PAH}$ concentration by $\mathrm{EqP}$ is converted to toxic units based on narcosis theory. The toxic units of individual PAH are summed together. If the sum exceeds a value of 1 , toxicity to benthic invertebrates is expected to occur (US EPA 2003). In this report, equilibrium partitioning $(\mathrm{EqP})$ is employed in predicting $\mathrm{PAH}$ exposure concentrations, and narcosis theory is applied to determine whether or not sufficient PAHs are present to cause 


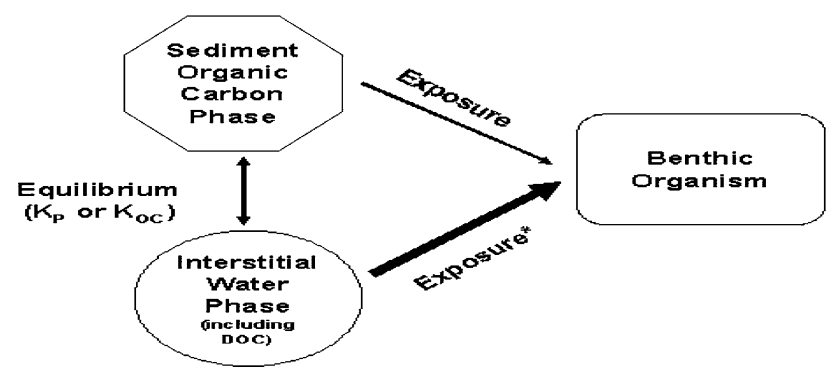

Fig. 1 Diagram of Important Sediment Phases Affecting the Bioavailability of PAHs in Sediments

adverse effects. This approach is based heavily upon the recently published EqP Sediment Benchmark (ESB) for PAH mixtures document prepared by the US EPA (2003). Hence, this report should be used in conjunction with US EPA (2003).

\section{Materials and Methods}

All chemicals, reagents and standards were, as far as qualitative parameters were concerned, in compliance with the regulations of the standardized and certified analytical methods. The sampling sites (Fig. 2) were divided into two (Ayetoro-Site A and Awoye-Site B). These are areas wit reported cases of oil spillage from Shell and Chevron facilities in Ondo State, southwestern part of Nigeria (Ololade and Lajide 2009). At different seasons (dry and wet) samples of sediments were collected randomly from each site based on APHA standard methods (Aderemi et al. 2003). Samples were collected and rapped inside aluminum foil after proper labeling. The samples were subsequently placed inside coolers containing ice-bag and transferred into the laboratory where they were preserved in the freezer prior to analysis. Organic carbon was determined following modified Walkley and Blacks method as described by Nelson and Sommers (1982).

About $100 \mathrm{~g}$ of partially thawed sediment samples were soxhlet extracted with dichlomethane. After saponification with $\mathrm{KOH}$ and partitioned with n-hexane using separating funnel. Internal standard (phenanthrene, anthracene, carbarzole and dibenzothiophene) were used. The final evaporation of the extracts was carried out under nitrogen gas and later chromatographed. The final extract was later analysed using GC-MS Hewlett-Packard (HP) 6890/5975 series instrument.The mass spectrometer was operated from 35 to 500 Dalton (SCAN mode). The peaks in the chromatogram were identified by comparison of the retention times and spectra of reference compounds with those in the sample. The peaks were quantified using the flame ionization detector (FID). The recovery and precision of the analytical procedure were tested using mixtures of some PAHs. Four PAHs (phenanthrene, anthracene, carbarzole and dibenzothiophene) were employed as surrogate standards. An average of three parallel determinations was carried out for the recovery study. The average percentage recoveries varied from $87 \%$ for phenanthrene to $102 \%$ for
Fig. 2 Map of the study area (inserted is the area map of Nigeria and Africa showing the geographical location)

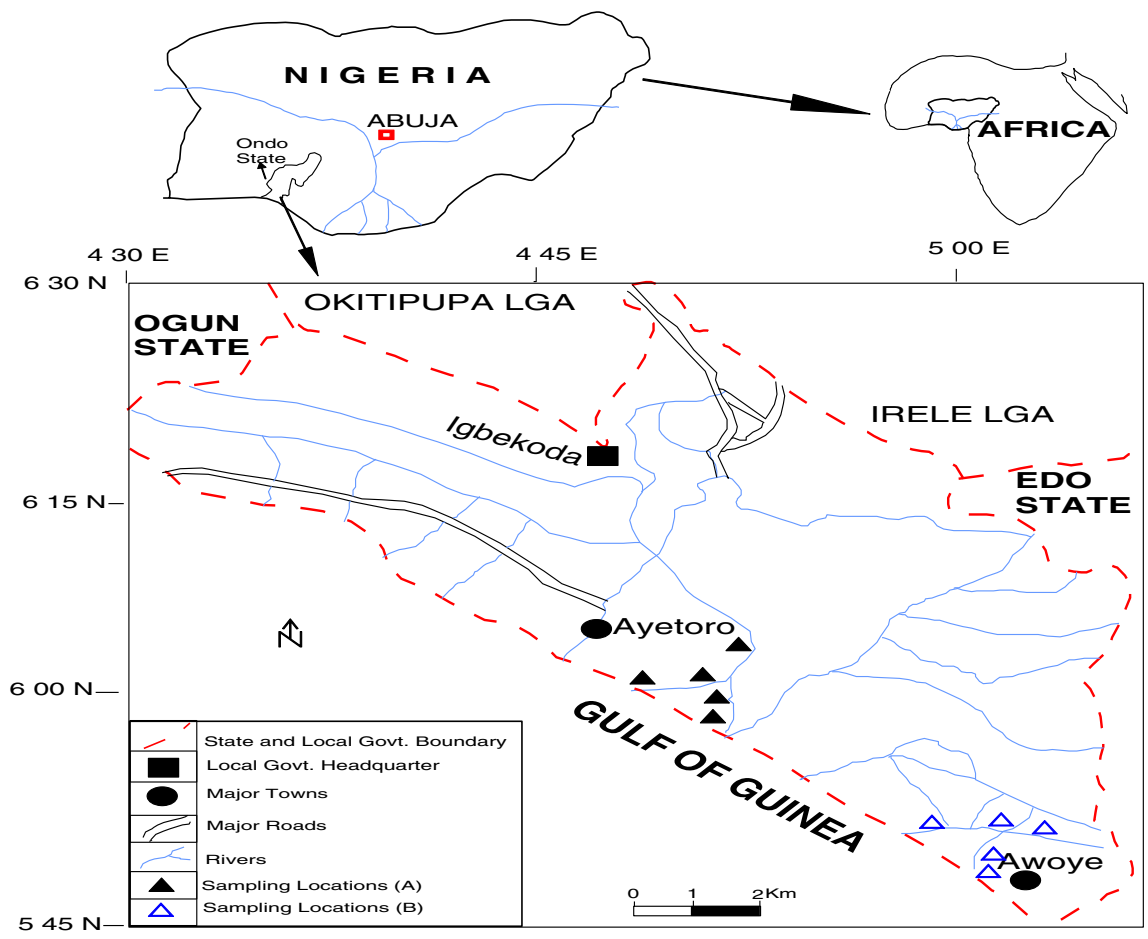


Table 1 Precision and recovery of standard PAH mixture

\begin{tabular}{llll}
\hline PAH & $\begin{array}{l}\text { Retention } \\
\text { time }(\mathrm{min})\end{array}$ & $\begin{array}{l}\text { Recovery }^{\mathrm{a}} \\
(\%)\end{array}$ & $\begin{array}{l}\text { Coefficient of } \\
\text { variation }(\%)\end{array}$ \\
\hline Anthracene $^{\mathrm{b}}$ & 30.186 & $102.30(0.71)$ & 11.34 \\
Carbazole $^{\text {Dibenzothiophene }}$ & 46.083 & $91.23(0.74)$ & 13.22 \\
Phenanthrene $^{\mathrm{b}}$ & 26.351 & $97.12(0.93)$ & 10.13 \\
\hline
\end{tabular}

${ }^{a}$ Recoveries of three parallel determinations; values in parentheses are standard deviation

${ }^{\mathrm{b}}$ Compounds on the USEPA priority pollutant list

anthracene. The relative standard deviation and coefficient of variation did not exceed $0.93 \%$ and $13.22 \%$ respectively for any compound (Table 1).

\section{Results and Discussion}

The concentrations of detectable PAHs in the sediment across the study area are presented in Fig. 3. The trend in the concentrations at both seasons are almost similar but with the PAHs concentrating more during the wet season. Significant positive correlation $(\alpha=0.01)$ were observed between PAHs concentration originating from the two respective sampling sites during both seasons $(r=0.998$ and 0.923 ) but without any significant mean difference ( $p=0.077$ and 0.118 , respectively). Though, dry season samples were first collected, it was thought that concentration during the wet season would be less due to the prevailing ecological conditions at that times. However, the increased levels during this period further implicate the continuous release of hydrocarbon residues into the area. It also re-affirms that sediments are capable of adsorbing organic pollutants such as PAHs (Aderemi et al. 2003; Ololade and Lajide 2009).

However, using the EqP and Narcosis model (Table 2), which are both evaluated with non-alkylated PAHs, four non-alkylated PAHs were identified and consequently used in calculating the toxic units associated with the sediment rather than the recommended 34 by US EPA (2003). Apart from the sediment concentrations and sediment organic carbon (i.e., site data), all other information needed to adopt the EqP approach are obtained from US EPA (2003). This approach is suitable especially when less than the required 34 PAHs have been chemically analyzed as applicable in the present study. The highest and least bioavailable concentrations of PAHs $\left(\mathrm{C}_{\mathrm{OC}, \mathrm{PAH}} \mu \mathrm{g} / \mathrm{g}_{\mathrm{OC}}\right)$ during the dry season (wet season in brackets) are 48.57 (63.00) and $0.68(0.30)$ as recorded in phenanthrene and dibenz(a,h)anthracene respectively (Table 2 ). These concentrations are more realistic indicator of bioavailable PAHs. Using the values and the organic carbon normalized toxicity value (Table 2, from US EPA 2003), the sum of the toxic units are 0.139 and 0.207 at site $A$ and B, respectively. These values are far less than the 1.0; hence, there is no likelihood that PAH toxicity to benthic organisms will occur. The sediments are therefore predicted not to exhibit chronic toxicity from PAHs (MacDonald and Ingersoll 2000; US EPA 2003). It must however be noted that sediment toxicity to benthic organisms can occur if the sum of toxic units is less than 1.0, but this will most likely be due to the presence of other toxicants including, possibly, unanalyzed PAHs.

Slight variations in PAH concentrations between sites suggests different sources of contamination. Changes in the PAH pattern may reflect changes in the source of PAHs such as coal, oil, gas, and petroleum combustion, and the resulting effect of combustion conditions. Based on the fact
Fig. 3 Mean concentrations of PAH in $(\mu \mathrm{g} / \mathrm{g}) *$ in sediments from Ondo coast, Nigeria.

* Concentrations are means of triplicate analysis. DS: dry season; WS: wet season, ** compounds on the USEPA priority pollutant list.

*** Cancer suspect

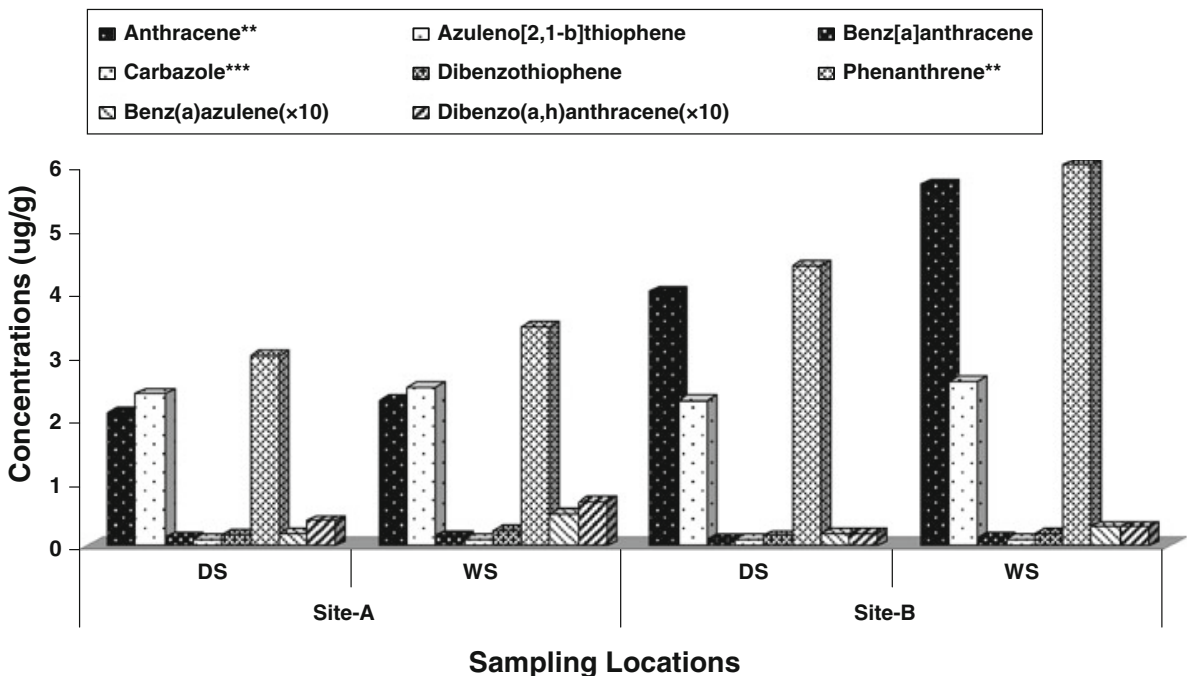


Table 2 Calculation of toxic units associated with sediment contaminated with four PAH across the two seasons

\begin{tabular}{llllr}
\hline PAH & $\begin{array}{l}\text { Concentration* } \\
(\mu \mathrm{g} / \mathrm{g})\end{array}$ & $\begin{array}{l}\text { COC,PAH** } \\
(\mu \mathrm{g} / \mathrm{g} \text { oC })\end{array}$ & $\begin{array}{l}\text { COC,PAH,FCV*** } \\
(\mu \mathrm{g} / \mathrm{goC})\end{array}$ & $0.055(0.099)$ \\
\hline Anthracene & $2.190(4.855)$ & $32.93(58.71)$ & 594 & $0.081(0.109)$ \\
Phenanthrene & $3.231(5.211)$ & $48.57(63.00)$ & 596 & $0.0027(0.0017)$ \\
Benz(a)anthracene & $0.151(0.121)$ & $2.26(1.45)$ & 841 & $0.0006(0.0003)$ \\
Dibenz(a,h)anthracene & $0.045(0.025)$ & $0.68(0.30)$ & 1123 & $\sum=0.1393(0.2070)$ \\
\end{tabular}

Values in parentheses are results of site-B. Site-A:TOC $=6.65 \%$; foc $=0.0665$ (goc/g); Site-B: TOC $=8.27 \%$; foc $=0.0827$ (goc/g). Toxicity value $(\mathrm{TU})=\mathrm{C}_{\mathrm{OC}, \mathrm{PAH}} / \mathrm{C}_{\mathrm{OC}, \mathrm{PAH}, \mathrm{FCV}}(\mathrm{US}$ EPA 2003)

$*$ Concentrations are mean of both seasons at each site; $* *$ organic carbon normalized PAH concentration $=\left(\mu \mathrm{g}\right.$ concentration $/ \mathrm{g}_{\mathrm{DRY}} \mathrm{wT} \times$ $100) \div \%$ TOC; $* *$ organic carbon normalized toxicity value (Obtained from US 2003)

$F C V$ final chronic value $(\mu \mathrm{g} / \mathrm{L})$

Fig. 4 a Composition pattern of PAH across both seasons by ring size at Site-A.

b Composition pattern of PAH across both seasons by ring size at Site-B a
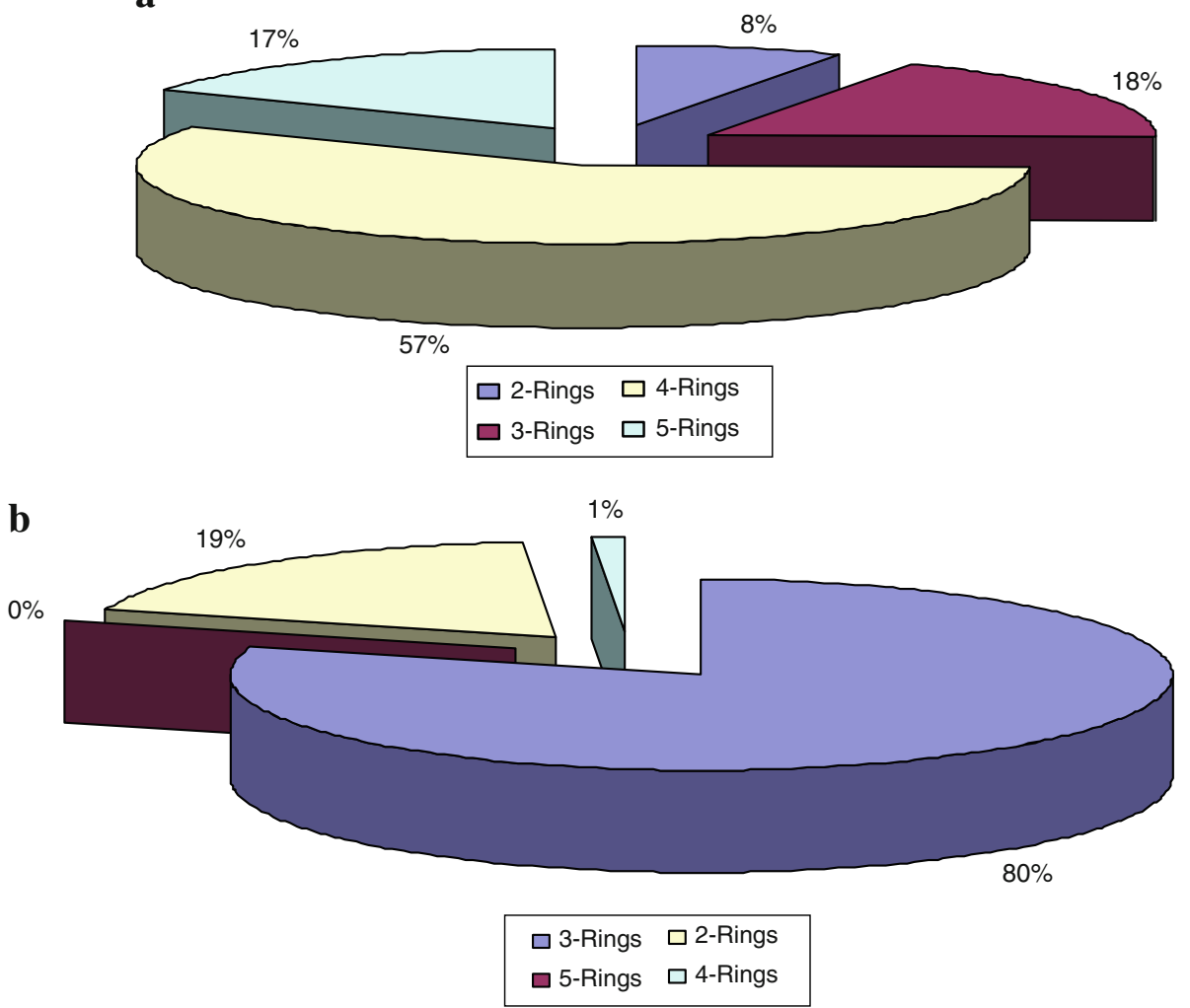

in Fig. 3, the LPAHs (<4rings) are the dominant hydrocarbons constituting about $97.1 \%$ and $98.7 \%$ at site-A and site-B respectively (Fig. 4a, b).

In the study, the TU did not suggests toxicity of PAH to benthic invertebrates based on narcosis model, however, probability for negative effects is high based on the fact that the concentration of PAHs measured in the sediments are comparable to other contaminated sites in which severe impacts have been observed (Ikenaka et al. 2005; Aderemi et al. 2003; Pavlora and Ivanora 2003). Thus, sedimentdwelling or burrowing organisms such as crabs, periwinkles e.t.c. are at the greatest risk especially during the wet season because PAHs tend to remain bound to organic sediment (Kannan et al. 2003, 2005; Koh et al. 2004). Aquatic organisms that reside on the sediment surface, restricted to the water column only, are likely to receive less concentration from the sediment - bound $\mathrm{PAH}$, and are therefore at less risk. It is also to be noted that some of the compounds identified (Fig. 3) in this study are those usually found in sediments, some of which have been reported to be carcinogenic and are on the US EPA priority list (Wang et al. 2008). The approach, particularly when used with other contaminated sediment assessment methods, offers risk assessors a useful tool for assessing the risk of PAHs to 
benthic invertebrates at hydrocarbon waste sites. Based on the results of the study, continuous PAH monitoring studies are warranted in sediment samples from the study area.

Acknowledgments The authors are very grateful to Dr. Stefan Louw and Désirée Prevoo of the gas chromatography - mass spectrometry laboratory, Central Analytical Faculty of Stellenbosch University, South Africa for assistance in the hydrocarbon analyses.

\section{References}

Aderemi OO, Olabode IA, Olalekan SF (2003) Isolation and determination of polycyclic aromatic hydrocarbons in surface runoff and sediment. Water Air Soil Pollut 147:245-261

Chen SJ, Su HB, Chang JE, Lee WJ, Huang KL, Hsieh LT, Huang YC, Lin WY, Lin CC (2007) Emissions of polycyclic aromatic hydrocarbons (PAHs) from the pyrolysis of scrap tires. Atm Environ 41(6):1209-1220

Di Toro DM, Zarba CS, Hansen DJ, Berry WJ, Swartz RC, Cowan CE, Pavlou SP, Allen HE, Thomas NA, Paquin PR (1991) Technical basis for establishing sediment quality criteria for nonionic organic chemicals using equilibrium partitioning. Environ Toxicol Chem 10:1541-1583

Ikenaka Y, Heesoo E, Eiki W, Fuyio K, Yinchi M (2005) Estimation of sources and inflow of Dioxins and Polycyclic Aromatic Hydrocarbons from the sediment core of Lake Suwa, Japan. Environ Pollut 138(3):529-537

Kannan K, Kober JL, Khim JS, Szymczyk K, Falandysz J, Giesy JP (2003) Polychlorinated biphenyls, polycyclic aromatic hydrocarbons and alkylphenols in sediments from Odra River and its tributaries, Poland. Toxicol Environ Chem 85:51-60
Kannan K, Johnson-Restrepo B, Yohn SS, Giesy JP, Long DT (2005) Spatial and temporal distribution of polycyclic aromatic hydrocarbons in sediments from Michigan inland lakes. Environ Sci Technol 39:4700-4706

Koh CH, Khim JS, Kannan K, Villeneuve DL, Senthil KK, Giesy JP (2004) Polychlorinated dibenzo-p-dioxins (PCDDs), dibenzofurans (PCDFs), biphenyls (PCBs), and polycyclic aromatic hydrocarbons (PAHs) and 2, 3, 7, 8- TCDD equivalents (TEQs) in sediment from the Hyeongsan River, Korea. Environ Pollut 132:489-501

MacDonald DD, Ingersoll CG, Berger TA (2000) Development and evaluation of consensus-based sediment quality guidelines for freshwater ecosystems. Arc Environ Contam Toxicol 39:20-31

Nelson PW, Sommers CE (1982) Total carbon, organic carbon and organic matter. In: Page AL (ed) Methods of soil analysis, 2nd edn. SSSA, Madison, WI, pp 539-579

Ololade IA, Lajide L (2009) Surveillance and source diagnostic investigation of hydrocarbon residues in sediments. J Environ Sci Health A 44:1033-1040

Pavlora A, Ivanora R (2003) Determination of petroleum hydrocarbons and PAHs in sludge from wastewater treatment basins. J Environ Monit 5:319-323

US EPA (2003) Procedures for the derivation of equilibrium partitioning sediment benchmarks (ESBs) for the protection of benthic organisms: PAH Mixtures. US Environmental Protection Agency, Office of Research and Development, Washington, DC. EPA/600/R-02/013, http://www.epa.gov/nheerl/publications/ files/PAHESB

Wang J, Nie Y, Luo X, Zeng EY (2008) Occurrence and phase distribution of polycyclic aromatic hydrocarbons in riverine runoff of the Pearl River Delta, China. Marine Pollut Bull 57: $767-774$ 